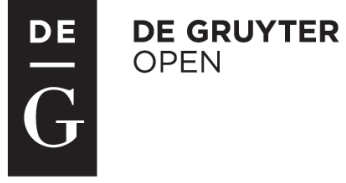

\title{
BLOOD IMMUNOLOGICAL AND BIOCHEMICAL INDICATORS IN TURKEY HENS FED DIETS WITH A DIFFERENT CONTENT OF THE YEAST YARROWIA LIPOLYTICA*
}

\author{
Anna Czech, Malwina Merska*, Katarzyna Ognik \\ Department of Biochemistry and Toxicology, Faculty of Biology and Animal Breeding, \\ University of Life Sciences in Lublin, Akademicka 13, 20-950 Lublin, Poland \\ •Corresponding author: malwina.merska@interia.pl
}

\begin{abstract}
The aim of this study was to determine immunological and biochemical blood indicators of turkey hens administered feed mixtures with 3 or $6 \%$ of Yarrowia lipolytica strain yeast as a dietary nutrient. The experiment was carried out on 240 turkey hens, aged from 1 to 16 weeks. The hens were randomly assigned to 3 experimental groups of 80 birds. Group I served as a control (K) and did not receive any experimental compounds. The turkey hens from experimental groups (YL3, YL6) were administered dried Yarrowia lipolytica yeast in two doses: 3\% (YL3) and 6\% (YL6) in feed mixtures. The study showed that the addition of Yarrowia lipolytica yeast in a dose of $3 \%$ but mainly in a dose of $6 \%$ stimulated the body's immune defence mechanisms, which was evidenced by the increase in plasma lysozyme, $\% \mathrm{KF}, \mathrm{IF}$, and reduction of monocyte ratio $\mathrm{H} / \mathrm{L}$ in turkey hens. The advantage of using Yarrowia lipolytica in the nutrition of turkey hens was also a decrease in the content of blood indicators of lipid peroxidation such as CHOL, TG and LDL-cholesterol fraction, and an increase in the percentage of HDL-cholesterol fraction. The use of yeast component in the feeding of turkey hens affected the health status of birds and contributed to proper (not deviating from the reference values) biochemical indicators of metabolism.
\end{abstract}

Key words: Yarrowia lipolytica, yeast, turkey hens, blood, immunological indices

Modern rearing methods are aimed at yielding the best production results at the lowest possible cost. To achieve this, farmers use e.g. new generation feed additives such as probiotics, prebiotics and synbiotics, which are mostly implicated in the stimulation of processes associated with better utilization of the basic nutrients, as well as vitamins and minerals (Stanley et al., 2004). Owing to their properties of maintaining or restoring the microbiological balance they have been shown to better regulate the gut microflora, and therefore directly affect the health status of animals (Al-Mansour et al., 2011; Auclair, 2001; Ashraf et al., 2013).

\footnotetext{
*Work financed by Department of Biochemistry and Toxicology, University of Life Sciences in Lublin.
} 
Apart from the aforementioned additives, a growing interest has recently been devoted to fodder yeast. Mainly the Saccharomyces cerevisiae (SC) yeast strain has been used for many years in the poultry production as a natural growth promoter (Stanley et al., 2004; Hooge et al., 2003; Al-Mansour et al., 2011). However, currently researchers are looking for a new yeast strain, whose components have remarkable physiological and biochemical properties and would be a rich source of nutrients, like e.g. Yarrowia lipolytica (YL) strain.

The research by Michalik et al. (2013) and our previous study (Woźnica and Czech, 2010 a) show that yeast of the species Yarrowia lipolytica have a high protein (about 45\%) and dry matter content (ca. 97\%), and a low content of crude ash (about $5 \%$ ). They are also a valuable source of vitamins, especially the B-group vitamins. They are characterized by vitamin $\mathrm{B}_{1}$ content of approx. $95 \mathrm{mg} \mathrm{kg}^{-1}$, and by $\mathrm{B}_{2}$ content of approx. $16 \mathrm{mg} \mathrm{kg}^{-1}$. They are also characterized by a high content of phosphorus, iron, sodium, and zinc. Yarrowia lipolytica are grown on an unpurified glycerol fraction from the production of fuel oil (Workman et al., 2013). They have been utilized primarily in practice for the production of citric acid (Levinson et al., 2007) and extracellular enzymes such as phosphatases, acid proteases, lipases or mannosidases (Czajgucka et al., 2003). The few studies carried out so far have demonstrated that the Yarrowia lipolytica yeast can also be used in a high-quality feed material as a link between the by-products from the production of biofuels and animal feed (Coelho et al., 2010). Currently, studies are underway on the use of Yarrowia lipolytica yeast in rearing various species of animals (Canibe et al., 2010; Hatlen et al., 2012) whereas there are few studies on poultry and more specifically on turkeys.

In order to verify the suitability of newly applied yeast strains (YL) it is important to choose the appropriate dose, which on the one hand stimulates the metabolic processes that lead to the improvement of health and consequently production effects, and on the other hand would not have an adverse effect on an animal organism. Choosing an appropriate dose of yeast should not be based only on their effectiveness in improving production effects, but also on the control of basic metabolic processes in the body during the administration of yeast biomass (Al-Mansour et al., 2011). In order to determine the general health status of an animal, the functioning of various organs and the possibility of capturing any disorders that could result from yeast additives administration, blood tests should be performed (Ganong, 2005). They allow comparing the results with the values obtained by other authors for different groups of animals, taking into account the physiological status, a technological group, living conditions and clinical observations.

Therefore, the aim of this study was to determine immunological and biochemical blood indicators of turkey hens administered a nutrient component - Yarrowia lipolytica yeast strain in doses of 3 and $6 \%$.

\section{Material and methods}

The experiment was carried out on 240 turkey hens of Big 6 line, aged from 1 to 16 weeks. The birds were randomly assigned to 3 experimental groups of 80 turkeys 
each, allocated to 5 replications of 16 birds each. The birds were kept in floor pens under zoohygienic conditions recommended for turkey fattening according to the Regulation of the Minister of Agriculture and Rural Development dated 15 February 2010 No. 56, item 344. The experimental procedure was approved by the II Local Ethical Commission for Experiments with Animals in Lublin (approval no. 19/2012).

Table 1. Chemical composition of the yeast Yarrowia lipolytica utilized in the experiment (Woźnica and Czech, 2010 b)

\begin{tabular}{lcc}
\hline & Item & Content \\
\hline Total protein & $45.5 \pm 2.66 \%$ \\
Dry matter & $97.30 \pm 0.11 \%$ \\
Metabolizable energy & $16.74 \mathrm{MJ} \mathrm{kg}^{-1}$ \\
Crude ash & $5.2 \pm 0.12 \%$ \\
Amino acids & $\mathrm{g} \mathrm{kg}$ d.m. \\
Aspartic acid & $25.9 \pm 0.89$ \\
Glutamic acid & $24.8 \pm 1.36$ \\
Lysine & $20.5 \pm 0.69$ \\
Methionine & $4.3 \pm 0.12$ \\
Threonine & $20.8 \pm 1.65$ \\
Tryptophan & $4.3 \pm 0.23$ \\
Cystine & $4.2 \pm 0.36$ \\
Leucine & $20.0 \pm 0.25$ \\
Isoleucine & $12.9 \pm 0.89$ \\
Valine & $15.8 \pm 1.36$ \\
Histidine & $7.8 \pm 0.36$ \\
Arginine & $13.5 \pm 0.21$ \\
Serine & $15.2 \pm 0.66$ \\
Alanine & $20.2 \pm 2.09$ \\
Phenylalanine & $12.3 \pm 0.36$ \\
Tyrosine & $20.6 \pm 1.39$ \\
Glycine & $12.6 \pm 0.36$ \\
Proline & $13.0 \pm 1.20$ \\
\hline
\end{tabular}

Group I served as a control $(\mathrm{K})$ and did not receive the yeast Yarrowia lipolytica. The turkey hens from experimental groups (YL3, YL6) were administered dried yeast Yarrowia lipolytica in two various doses of 3\% (YL3) and 6\% (YL6) in feed mixtures. Birds from all groups received feed mixtures that were composed based on a wheat, triticale, soybean meal, rapeseed cake, potato protein (Starter - 1-3 weeks) and soybean oil. All the mixtures were isonitrogenous and isoenergetic. The nutrient content in $1 \mathrm{~kg}$ of feed mixture given to turkey hens was: $\mathrm{TP}-28.76 \%$; $\mathrm{ME}-$ $2700 \mathrm{kcal} \mathrm{kg}^{-1}$; Lys - 1.9\%; Met+Cys - 0.6\%; Ca - 1.4\%; P - 0.7\% (1-3 weeks); $\mathrm{TP}-24.5 \%$; ME - $2800 \mathrm{kcal} \mathrm{kg}{ }^{-1}$; Lys $-1.6 \%$; Met $+\mathrm{Cys}-0.6 \%$; Ca $-1.3 \%$; P $0.65 \%$ (4-7 weeks); TP-22.50\%; ME - $2800 \mathrm{kcal} \mathrm{kg}{ }^{-1}$; Lys $-1.4 \%$; Met+Cys $-0.5 \%$; 
$\mathrm{Ca}-1.15 \% ; \mathrm{P}-0.6 \%$ (8-12 weeks); and TP - 18.50\%; ME - $2900 \mathrm{kcal} \mathrm{kg}^{-1}$; Lys $1.1 \%$; Met+Cys $-0.4 \%$; Ca $-1.0 \%$; $\mathrm{P}-0.5 \%$ (13-16 weeks). All birds were kept under the same management, environmental and hygienic conditions except for different dietary levels of yeast. Chemical composition of the yeast Yarrowia lipolytica was presented in Table 1. Feed and fresh water was provided ad libitum throughout the experimental period.

Blood was sampled for analyses from the brachial vein of 10 birds from each group at the end of the experimental period (16 weeks of age). Blood was sampled to heparinized $10-\mathrm{mL}$ test tubes under the supervision of a veterinarian. Immunological tests included determination of proportions (percentage) of heterophils (HET), lymphocytes (LYM), monocytes (MONO), eosinophils (EOS), and basophils (BASO) (Feldman et al., 2000). The heterophil/lymphocyte ratio (H/L), an indicator of stress in birds (Gross and Siegel, 1983), was calculated by dividing the number of heterophils in $1 \mathrm{~mL}$ of peripheral blood by the number of lymphocytes. Blood samples were additionally analysed for leukocyte phagocytic activity against Staphylococcus aureus 209P strain, expressed as a percentage of phagocytic cells (\% KF) and phagocytic index (IF), as well as for the absorption and reduction of heterophils by nitroblue tetrazolium (NBT test) - according to the method of Park et al. (1968). Serum lysozyme activity was determined with the turbidimetric method (Siwicki and Dunier, 1993). Using monotests by Cormay company, blood plasma was assayed spectrophotometrically for levels of the selected biochemical indicators, that is, total protein (TP), glucose (GLU), uric acid (UA), urea (UREA), creatinine (CREAT), bilirubin (BIL), total cholesterol (CHOL), triacylglycerides (TG), and high-density lipoprotein (HDL). Low-density lipoprotein (LDL) fraction of cholesterol was calculated using Friedewald et al. (1972) formula: LDL-chol $\left(\mathrm{mmol} \mathrm{l}^{-1}\right)=$ total cholesterol - HDL-chol - triacylglycerides /2.2. Besides, the activities of selected enzymes were identified, i.e. alanine aminotransferase (ALT), aspartate aminotransferase (AST), alkaline phosphatase (ALP) and lactate dehydrogenase (LDH), also using ready test kits by Cormay company. Assays were carried out using a UNICAM 939 spectrophotometer.

Statistical computations were carried out using Statistica Ver 6.1.G software. For all analysed dependent variables, one-way analysis of variance ANOVA was conducted according to the following model:

$$
y_{i j}=\mu+a_{i}+e_{i j}
$$

where:

$$
\begin{aligned}
& \mu \text { - total mean, } \\
& a_{i}-\text { stable effect of } \mathrm{i} \text {-th additive for } \mathrm{i}=0,1, \ldots, 3 \text { (for control } \mathrm{i}=0 \text { ), } \\
& e_{i j}-\text { random error has normal distribution } \mathrm{N}(0,) .
\end{aligned}
$$

The significance of differences between means was determined with the one-way analysis of variance test ANOVA, at a significance level of 0.05 . 


\section{Results}

Significantly lower amounts of heterophils and H/L ratio were determined in turkey hens receiving $6 \%$ of Yarrowia lipolytica (YL) yeast in the feed mixture (Table 2 ). An inverse relationship was recorded for the amount of monocytes and IF value. These differences were statistically significant $(\mathrm{P} \leq 0.05)$. The level of lysozyme and $\% \mathrm{KF}$ in blood of turkey hens receiving $3 \%$ and $6 \%$ of YL in the feed mixture were significantly higher compared to the respective values in blood of the control birds $(\mathrm{P} \leq 0.05)$ (Table 2).

Table 2. Levels of immunological blood indicators of turkey hens in the 16th week of life

\begin{tabular}{l|c|c|c|c}
\hline \multirow{2}{*}{ Item } & \multicolumn{3}{|c|}{ Experimental groups } & \multirow{2}{*}{ SEM } \\
\cline { 2 - 3 } & $\mathrm{K}$ & YL3 & YL6 & \\
\hline Leucogram (\%) & & & \\
HET & $46.45 \mathrm{c}$ & $38.00 \mathrm{~b}$ & $28.10 \mathrm{a}$ & 0.489 \\
LYM & 43.00 & 43.25 & 48.45 & 0.573 \\
MONO & $2.75 \mathrm{a}$ & $7.70 \mathrm{~b}$ & $11.90 \mathrm{c}$ & 0.136 \\
EOS & 4.70 & 6.75 & 6.20 & 0.109 \\
BAZO & 3.15 & 4.30 & 5.35 & 0.187 \\
H/L & $1.06 \mathrm{c}$ & $0.88 \mathrm{~b}$ & $0.54 \mathrm{a}$ & \\
Lysozyme; $\mu \mathrm{g} \mathrm{ml}^{-1}$ & $2.18 \mathrm{a}$ & $2.46 \mathrm{~b}$ & $2.52 \mathrm{~b}$ & 0.202 \\
\% KF & $40.67 \mathrm{a}$ & $47.67 \mathrm{~b}$ & $51.08 \mathrm{~b}$ & 0.522 \\
IF & $5.17 \mathrm{a}$ & $5.46 \mathrm{ab}$ & $5.92 \mathrm{~b}$ & 0.192 \\
NBT & 25.54 & 27.17 & 24.66 & 0.467 \\
\hline
\end{tabular}

$\mathrm{a}, \mathrm{b}$ - values in the same rows with different letters differ significantly at $\mathrm{P} \leq 0.05$.

A significant increase in the content of plasma total protein and urea was observed in the YL6 group compared to the control group (K). In the blood plasma of birds receiving both $3 \%$ and $6 \%$ of YL yeast in the feed mixture a significant increase was recorded in levels of uric acid, creatinine and bilirubin (Table 3).

The level of aspartate aminotransferase (AST) in blood plasma was significantly lower $(\mathrm{P} \leq 0.05)$ in birds receiving $6 \%$ of YL yeast in the feed. A significantly lower activity of alanine aminotransferase (ALT) and alkaline phosphatase (ALP) enzymes was noted in the blood plasma of birds receiving 3\% of YL in feed compared to the other experimental groups. In contrast, the lowest activity of lactate dehydrogenase (LDH) in the blood plasma was recorded in the control group (Table 3).

The analysis of contents of lipid profile indicators in the plasma of birds receiving feed mixtures with 3\% and 6\% addition of Yarrowia lipolytica yeast showed a decrease in total cholesterol, LDL-cholesterol fraction, and triacylglycerides $(\mathrm{P} \leq 0.05)$. In birds from the YL6 group, a significant increase was reported in the percentage of HDL-cholesterol fraction and a decrease in the HDL/LDL ratio compared to the control group (K) (Table 4). 
Table 3. Level of biochemical indicators and the activity of enzymes in blood of turkey hens in the 16th week of life

\begin{tabular}{|c|c|c|c|c|}
\hline \multirow{2}{*}{ Item } & \multicolumn{3}{|c|}{ Experimental groups } & \multirow{2}{*}{ SEM } \\
\hline & K & YL3 & YL6 & \\
\hline $\mathrm{TP}\left(\mathrm{g} \mathrm{dl}^{-1}\right)$ & $37.6 \mathrm{a}$ & $38.0 \mathrm{a}$ & $39.5 \mathrm{~b}$ & 0.278 \\
\hline GLU $\left(\mathrm{mmol} \mathrm{l}^{-1}\right)$ & 15.39 & 15.88 & 14.80 & 0.117 \\
\hline $\mathrm{UA}\left(\mathrm{mmol} \mathrm{l}^{-1}\right)$ & $214.33 \mathrm{a}$ & $261.55 \mathrm{~b}$ & 294.14 b & 6.70 \\
\hline UREA $\left(\mathrm{mmol} \mathrm{l}^{-1}\right)$ & $0.416 \mathrm{a}$ & $0.562 \mathrm{~b}$ & $0.709 \mathrm{c}$ & 0.022 \\
\hline $\operatorname{CREAT}\left(\mu \mathrm{mol} \mathrm{l}^{-1}\right)$ & $22.58 \mathrm{a}$ & $30.17 \mathrm{~b}$ & $28.33 \mathrm{~b}$ & 0.563 \\
\hline $\operatorname{BIL}\left(\mu \mathrm{mol} \mathrm{l}^{-1}\right)$ & $9.23 \mathrm{a}$ & $10.88 \mathrm{~b}$ & $11.75 \mathrm{~b}$ & 0.286 \\
\hline \multicolumn{5}{|l|}{ Enzymatic activity } \\
\hline $\operatorname{AST}\left(\mathrm{U}^{-1}\right)$ & $164.44 \mathrm{~b}$ & $155.07 \mathrm{~b}$ & $137.21 \mathrm{a}$ & 2.82 \\
\hline $\operatorname{ALT}\left(\mathrm{U} \mathrm{l}^{-1}\right)$ & $6.42 \mathrm{~b}$ & $5.85 \mathrm{a}$ & $8.01 \mathrm{c}$ & 0.14 \\
\hline $\operatorname{ALP}\left(\mathrm{U}^{1-1}\right)$ & $969.39 \mathrm{~b}$ & $918.88 \mathrm{a}$ & $972.43 \mathrm{~b}$ & 5.55 \\
\hline $\mathrm{LDH}\left(\mathrm{U}^{-1}\right)$ & $503.63 \mathrm{a}$ & $525.21 \mathrm{~b}$ & $629.58 \mathrm{c}$ & 7.74 \\
\hline
\end{tabular}

$\mathrm{a}, \mathrm{b}$ - values in the same rows with different letters differ significantly at $\mathrm{P} \leq 0.05$.

Table 4. Lipid parameters in blood of turkey hens in the 16th week of life

\begin{tabular}{l|c|c|c|c}
\hline \multirow{2}{*}{\multicolumn{1}{c|}{ Item }} & \multicolumn{3}{c|}{ Experimental groups } & \multirow{2}{*}{ SEM } \\
\cline { 2 - 4 } & $\mathrm{K}$ & YL3 & YL6 & \\
\hline CHOL $\left(\mathrm{mmol} \mathrm{l}^{-1}\right)$ & $3.37 \mathrm{~b}$ & $2.88 \mathrm{a}$ & $2.75 \mathrm{a}$ & 0.048 \\
HDL $\left(\mathrm{mmol} \mathrm{l}^{-1}\right)$ & 1.94 & 1.82 & 1.81 & 0.027 \\
TG $\left(\mathrm{mmol} \mathrm{l}^{-1}\right)$ & $0.474 \mathrm{~b}$ & $0.397 \mathrm{a}$ & $0.393 \mathrm{a}$ & 0.015 \\
LDL $\left(\mathrm{mmol} \mathrm{l}^{-1}\right)$ & $0.456 \mathrm{~b}$ & $0.300 \mathrm{a}$ & $0.250 \mathrm{a}$ & 0.021 \\
HDL $(\%)$ & $58.02 \mathrm{a}$ & $63.97 \mathrm{ab}$ & $66.93 \mathrm{~b}$ & 1.28 \\
HDL/LDL & $1.75 \mathrm{~b}$ & $1.59 \mathrm{ab}$ & $1.53 \mathrm{a}$ & 0.034 \\
\hline
\end{tabular}

$\mathrm{a}, \mathrm{b}$ - values in the same rows with different letters differ significantly at $\mathrm{P} \leq 0.05$.

\section{Discussion}

Research carried out so far indicates that one of the main effects of yeast use in animal feeding is improvement of production effects (Reisinger et al., 2012; Tabidi et al., 2013). However, this has not been confirmed in the case of adding 3\% and $6 \%$ of Yarrowia lipolytica (YL) strain yeast to feed mixtures for turkey hens (Merska et al., 2013). In this study, the FCR reached $2.68 \mathrm{~kg} \mathrm{~kg}^{-1}$ in the control group, whereas in both experimental groups receiving $3 \%$ and $6 \%$ addition of YL yeast it was 2.76 and $2.805 \mathrm{~kg} \mathrm{~kg}^{-1}$, respectively $(\mathrm{P} \leq 0.05)$. Furthermore, in the experiment there have been no death losses. Kanat and Calialar (1996), in their study on the use of Saccharomyces cerevisiae (SC) strain in poultry feeding reported that active dry yeast effectively increased body weight gains without affecting feed conversion ratio. In turn, Merska et al. (2013) found that in turkey hens administered feed mixtures with $6 \%$ addition of YL the final body weights were lower by about $3.5 \%$ compared to the control group, whereas the feed intake and feed conversion remained at a similar 
level in groups K, DY3 and DY6. In contrast, many studies show a positive effect of SC yeast applied in poultry feeding on production parameters (Reisinger et al., 2012; Tabidi et al., 2013), but especially on the stimulation of body immune response (modulation of immunity) (Shashidhara and Devegowda, 2003; Gao et al., 2008) and promotion of intestinal microflora growth (Spring et al., 2000), which may improve digestibility of nutrients and, consequently, strengthen the immunological defence of animals (Özsoy and Yalçin, 2011). Proper evaluation of immune status is not easy, because increased values of indicators reflecting the immune response may result from pathological condition or from the immunostimulation of the system through the use of the so-called incentive immunostimulators such as yeasts.

The present study demonstrates that dietary administration of Yarrowia lipolytica strain especially in a $6 \%$ dose stimulates the immune response of turkey hens. This was indicated by increased levels of: lysozyme, \% KF, IF, monocytes, and decreased $\mathrm{H}: \mathrm{L}$ value in relation to the control group. The stimulating effect of the applied yeasts on the immune system was also confirmed in a study by Gao et al. (2008) where the use of yeast (e.g. SC) in poultry feeding was found to stimulate the immune response of the body (to modulate immunity).

Likewise in the study by Gao et al. (2008), the increase in the content of lysozyme which is mainly secreted by phagocytes and is a nonspecific immune effector in this study, was linear. The increased lysozyme concentration in birds supplemented with yeast culture (YC) can break down the polysaccharide walls of many types of bacteria and thus ensure protection against infection. The increased lysozyme content in yeast culture-treated birds suggests that more phagocytes were activated with the inclusion of YC. Therefore, YC may intensify the nonspecific immunity of birds. A recent study by Jensen et al. (2008) supports the role of yeasts in innate immune function. Heterophils and monocytes, which belong to the innate immune system, have the ability to phagocyte bacteria and parasites to protect the animal against primary infections (Harmon, 1998; Huff et al., 2007). Reduced count of heterophils $(\mathrm{P} \leq 0.05)$ and increased level of monocytes $(\mathrm{P} \leq 0.05)$ in the blood of birds receiving YL addition in feed mixtures indicates the activation of mechanisms of innate immunity. Heterophils are also responsible for tissue damage by accumulation in inflamed tissue and forming heterophil granulomas that are morphologically similar to inflammatory lesions in reptiles (Harmon, 1998). They are non-specific cells that proliferate to the tissues during body response to the inflammatory processes (Jurd, 1994; Maxwell and Robertson, 1998; Ots and Hõrak, 1998). The number of these granulocytes increases in response to prolonged bacterial and fungal infections and abnormalities associated with diet and stress (Maxwell and Robertson, 1998). These cells are the first line of defence against microbes located in the lungs and air sacs (Harmon, 1998).

It is also believed that the proportion of lymphocytes and heterophils (H:L) allows assessing the efficiency of the immune system and health condition of birds (Dufva and Allander, 1996; Ots and Hõrak, 1996). In the experiment, this ratio decreased with the increase of yeast share in feed mixture, compared to the control group, which should be considered a positive effect. According to Jones et al. (1995) and Davis et al. (2008), the increase in the H:L ratio most commonly occurs in patho- 
logical states of stress, then growth of heterophils is a consequence of mobilization of the immune system to phagocytosis. On the other hand, Huff et al. (2007) reported an increase in heterophils (percentage of leucocytes) in whole blood, in a study in which turkeys were fed a yeast extract and challenged with E. coli. Numerous studies, summarized by Kogan and Kocher (2007), have shown that yeast derivatives, such as $\beta$-glucan fractions, enhance the functional status of macrophages; however, little is known about the effect of yeast derivatives on the number of monocytes, the precursor of macrophages. Changes in blood cell profile in broiler chicks as affected by yeast supplementation have been reported as well (Saied et al., 2011). According to Auclair (2001), the mechanisms of action generally involved to explain the benefits of yeast supplementation in turkey species include stimulation of brush border disaccharides, anti-adhesive effect against pathogens, stimulation of non-specific immunity, toxin action inhibition, and antagonistic effect against pathogenic microorganisms. This effect of yeast is due to the presence (on the part of internal cell wall) of glucans that are constituted by the main chain of beta-(1-3)-linked D-glucose molecules to which there are attached linear branch chains of beta-(1-6) related residues. These branch chains of glucans have the capacity to activate the innate immune system, thereby enhancing the defence barriers and providing protection against a variety of infections (Raa, 1996; Mikulski et al., 2008; Soltanian et al., 2009). The mechanism of the stimulation of inflammatory response has been characterized, and involves a specific glucan receptor which is present on peripheral blood leukocytes and extravascular macrophages (Czop, 1986). Activation of this receptor with glucan stimulates the amplification of host defenses, which involves a cascade of interactions primarily mediated by macrophages and macrophage-derived products such as cytokines. According to Song and Di Luzio (1979), glucan can be considered as "immunoamplifier".

All changes occurring in the immune system may indirectly affect the course of biochemical processes taking place in the body (Özsoy and Yalçin, 2011). Considering that in the reported experiment the addition of YL yeast to feed mixtures for turkey hens has contributed to the stimulation of immune mechanisms and on the other hand did not result in significant improvement of production effects (especially at $6 \%$ dose of yeast in the feed mixture the production effects were even slightly worse than in the control - Merska et al., 2013), it is likely to be linked with the applied dose of yeast. Too high a dose of yeast could disturb the course of the metabolic processes. In view of that, liver function was evaluated in this study based on biochemical and enzymatic blood indicators. Both turkey hens receiving 3\% or 6\% addition of Yarrowia lipolytica in feed mixture showed no significant variation in the content of total bilirubin and cholesterol, as well as enzymes such as aspartate aminotransferase (AST), alanine aminotransferase (ALT), lactate dehydrogenase (LDH), alkaline phosphatase (ALP) compared to values reported by Mazurkiewicz (2005). Also, there were no deviations from the value adopted as a reference (Mazurkiewicz, 2005) regarding the content of TP, GLU, UA, UREA and CREAT in all experimental groups. Noteworthy is, however, that the values of plasma indicators (such as blood UA, UREA, CREAT, BIL, LDH) were significantly higher when compared to the control group, especially in turkey hens receiving $6 \%$ of YL in the feed mixture. The 
increased values of protein indices could result from the introduction to feed mixture of more available protein originating in the yeast. In addition, an increase in ALT, LDH and a slight increase in ALP in the group with $6 \%$ dose of yeast in feed mixture may also explain the increased effect of protein metabolism. However, the lack of regularity in the formation of all liver enzyme profiles as affected by the increasing level of yeast in feed mixtures does not allow explicit determination of the impact of this factor.

Similar results in turkey hens receiving dietary yeast at the rate of 1,2 and $3 \% \mathrm{SC}$ were also obtained by Yalçın et al. (2008) in serum levels of total protein, triglyceride, cholesterol, ALT, AST and ALP; however, the differences did not show statistical significance but merely tendencies. But still Yalçın et al. (2008) observed that serum uric acid was increased $(\mathrm{P}<0.05)$ by dietary yeast culture supplementation. Onifade et al. (1999a) reported that serum protein level was decreased and the serum levels of cholesterol, ALT, AST and ALP were increased with dietary yeast culture in rabbits. Yeasts are claimed to influence body lipids. According to Paryad and Mahmoudi (2008), dietary addition of Saccharomyces cerevisiae helps to reduce abdominal fat in poultry, which was also confirmed in our previous research (Merska et al., 2013), and to reduce the content of total cholesterol and LDL-cholesterol fraction and TG in blood plasma (Paryad and Mahmoudi, 2008). According to Abdelrahman (2013), abdominal fat is highly correlated (0.6 to 0.9 ) with the total carcass lipids and is used as the main criterion reflecting excessive fat deposition in broiler carcass. Therefore, there is a substantial potential for using yeast culture to reduce fat content and to improve meat quality.

The present results show that turkey administered feed mixtures with $3 \%$ and $6 \%$ YL had significantly lower plasma cholesterol, triglycerides, LDL-cholesterol fraction, and higher plasma \%HDL (but only in the group with $6 \%$ dose of YL). However, with an increasing level of YL in the experimental diet, LDL-cholesterol fraction, total cholesterol and triacylglyceride concentrations were not significantly reduced. Our observations corroborated data published by some authors (Abdulrahim et al., 1996; De Smet et al., 1998; Onifade et al., 1999 b; Panda et al., 2001; Kannan et al., 2005; Gudev et al., 2008; Paryad and Mahmoudi, 2008) who stated that there was a decrease in plasma cholesterol for chicks fed diets containing SC yeast and different probiotics. Reduction in circulating cholesterol with supplemental yeast was remarkable and agrees with the results of other researchers (Onifade et al., 1997; Onifade, 1999 b) that the addition of innocuous microorganisms (including yeast) to diet for rabbits and broiler chickens decreased serum cholesterol, triglycerides and phospholipids.

Yeast like prebiotics could contribute to the regulation of serum cholesterol concentrations by deconjugation of bile acids. Since the excretion of deconjugated bile acids is enhanced and cholesterol is its precursor, more molecules are spent for recovery of bile acids (Klaver and Van der Meer, 1993; De Smet et al., 1998; Kannan et al., 2005). As a result of increased synthesis of this acid, the level of serum cholesterol is expected to be reduced. Klaver and Van der Meer (1993) suggested that co-precipitation with bile acids might be of importance for decreasing serum cholesterol concentrations. 
The study showed that the addition of Yarrowia lipolytica yeast in a dose of $3 \%$ but mainly in a dose of $6 \%$ stimulated the body's immune defence mechanisms, which was evidenced by the increase in plasma lysozyme, \% KF, IF, and reduction of monocyte ratio $\mathrm{H} / \mathrm{L}$ in the blood of turkey hens. An advantage of using Yarrowia lipolytica in turkey hen feeding is also a decrease in the content of blood lipid peroxidation indicators such as CHOL, TG and LDL-cholesterol fraction, and increase in the percentage of HDL-cholesterol fraction. Dietary administration of yeast in turkey hen feeding had no effect on the health status of birds, as evidenced by the proper weight gains of birds (Merska et al., 2013), and proper (not deviating from the reference values) biochemical indicators of metabolism.

\section{References}

A b d e $1 \mathrm{r}$ a h m a n M.M. (2013). Effects of feeding dry fat and yeast culture on broiler chicken performance. Turk. J. Vet. Anim. Sci., 37: 31-37.

A bdulrahim S.M., Haddad M.S.Y., Has hl a moun E.A.R., Robin son R.K. (1996). The influenced of Lactobacillus asidophilus and Bacitracin on layer performance of chickens and cholesterol content of plasma and egg yolk. Brit. Poultry Sci., 37: 341-346.

A 1-Mansour S., A 1-Khalf A., A 1-Homidan I., F ath i M.M. (2011). Feed efficiency and blood hematology of broiler chicks given a diet supplemented with yeast culture. Int. J. Poultry Sci., 10: 603-607.

Ashraf S., Zaneb H., Yousaf M.S., Ijaz A., Sohail M.U., Muti S., Usman M.M., Ij a z S., R ehman H. (2013). Effect of dietary supplementation of prebiotics and probiotics on intestinal microarchitecture in broilers reared under cyclic heat stress. J. Anim. Physio. Anim. Nutr., 97: 68-73.

A u c la ir E. (2001). Yeast as an example of the mode of action of probiotics in monogastric and ruminant species. In: Feed manufacturing in the Mediterranean region. Improving safety: From feed to food, Brufau J. (ed.). Zaragoza: CIHEAM Cahiers Options Méditerranéennes., 54: 45-53.

Canibe N., Pedersen A.ř, Jensen B.B., Jespersen L. (2010). Microbiological and biochemical characterization of fermented liquid feed samples from 40 Danish farms. Liv. Sci., 134: $158-161$.

C o e 1 h o M.A.Z., A m a r a 1 P.F.F., B e 1 o I. (2010). Yarrowia lipolytica: an industrial workhorse. In: Current Research, Technology and Education Topics in Applied Microbiology and Microbial Biotechnolog, A. Mendez-Vilas (ed.), pp. 644-930.

Czajgucka A., Chrzanowska J., Juszczyk P., Szołtysik M., Wojtatowicz M. (2003). The proteolytic activity of yeast strains from Rokpol cheese (in Polish). Acta Sci. Pol. Biotechnol., 2: 73-81.

C z o p J.K. (1986). Characterization of a phagocytic receptor for beta-glucan on macrophages cultured from murine bone marrow. Path. Immunopath. Res., 5: 286-296.

D a vis A.K., M a n y D.L., M a er z J.C. (2008) The use of leukocyte profiles to measure stress in vertebrates: a review for ecologists. Funct. Ecol., 22: 760-772.

De Smet I., De Boeever P., Verstraete W. (1998). Cholesterol lowering in pigs through enhanced bacterial bile salt hydrolase activity. Br. J. Nutr., 79: 185-194.

D ufva R., A 11 ander K. (1996). Variable effects of the Hen Flea Ceratophyllus gallinae on the breeding success of the Great Tits Parus major in relation to weather condition. Ibis, 138: 772-777.

F e $1 \mathrm{~d}$ m a n B.J., Z in k i N., J a in P. (2000). Schalm's Veterinary Hematology. Lippincott and Wilkins, Philadelphia.

Fri e d e w a ld W.T., L e v y R.I., Fre dri c k s o n D.S. (1972). Estimation of the plasma low-density lipoprotein cholesterol, without use of the preparative ultracentrifuge. Clin. Chem., 18: 499-502.

G a n o n g W. (2005). Review of Medical Physiology. McGraw-Hill. 
Ga o J., Zhang H.J., Yu S.H., Wu S.G., Yoon I., Qu ig le y J., G a o Y.P., Qi G.H. (2008). Effects of yeast culture in broiler diets on performance and immunomodulatory functions. Poultry Sci., 87: $1377-1384$.

Gros s W.B., S i e ge 1 H.S. (1983). Evaluation of the heterophil/lymphocyte ratio as a measure of stress in chickens. Avian Dis., 27: 972-979.

Gudev D., P o pova-Ralcheva S., Moneva P., I g n a tova M. (2008). Effect of the probiotic "Lactona" on some biological parameters and nonspecific resistance in neonatal pigs. Biotechnol. Anim. Husb., 24: 87-96.

Harmon B.G. (1998). Avian heterophils in inflammation and disease resistance. Poultry Sci., 77: $972-977$.

Hatlen B., B erge G.M., Od o m J.M., Mundheim H., Ruyter B. (2012). Growth performance, feed utilization and fatty acid deposition in Atlantic salmon, Salmo salar L., fed graded levels of high-lipid/high-EPA Yarrowia lipolytica biomass. Aquaculture, 364-365: 39-47.

Huff G.R., Huff W.E., Rath N.C., Solis de los Santos F., Farnell M.B., Donoghu e A.M. (2007). Influence of hen age on the response of turkey poults to cold stress, Escherichia coli challenge, and treatment with a yeast extract antibiotic alternative. Poultry Sci., 86: 636-664.

J e n s e n G.S., P a t ter s on K.M., Yo on I. (2008). Yeast culture has anti-inflammatory effects and specifically activates NK cells. Comp. Immunol. Microbiol. Infect., 31: 487-500.

J u r d R.D. (1994). Reptiles and birds. In: Immunology: a comparative approach, Turner R.J. (ed.), Wiley, Chichester, pp. 137-172.

K a n a t R., C a li a la r S. (1996). A research on the comparison effect on broiler chickens performance of active dried yeast and inactivated and stabilized probiotic yeast supplemented to the rations in different levels. Poultry Sci., 75 (Suppl. 1), p. 123.

Kannan M., Karunakaran R., B a lakrishnan V., Prabhakar T.G. (2005). Influence of prebiotics supplementation on lipid profile of broilers. Int. J. Poultry Sci., 12: 994-997.

K laver F.A.M., Van der Me e r R. (1993). The assumed assimilation of cholesterol by Lactobacilli and Bifidobacterium bifidum is due to their bile salt-deconjugating activity. Appl. Environ. Metab., 59: 1120-1124.

K o gan G., K o cher A. (2007). Role of yeast cell wall polysaccharides in pig nutrition and health protection. Livest. Sci., 109: 161-165.

L e vin s o n W.E., K u r z m a n C.P., K u o T.M. (2007). Characterization of Yarrowia lipolytica and related species for citric acid production from glycerol. Enzyme Microb. Techn., 41: 292-295.

M a x w e 11 M.H., R o b e r t s o n G.W. (1998). The avian heterophil leucocyte: a review. World Poultry Sci., 54: $155-178$.

Mazurki ew i z M. (ed.). (2005). Diseases of poultry (in Polish). Wyd. AR Wrocław.

Mers k a M., C z e c h A., O g n i k K. (2013). The effect of different doses of dried yeast Yarrowia lipolytica on production effects of turkey hens and hematological indicators of blood. Annales UMCS sec. EE, 31: 35-41.

Michalik B., B i el W., L u b ow i ck i R., J a c y n o E. (2013). Chemical composition and biological value of proteins of the yeast Yarrowia lipolytica growing on industrial glycerol. Can. J. Anim. Sci., published on the web 31 October 2013, 10.4141/CJAS2013-052.

Mikulski D., Kozłows ki K., Jank ow s ki J., B lok J., S ob ol ew s ki Z. (2008). Efficacy of yeast extract Saccharomyces cerevisiae in turkey feeding (in Polish). Med. Weter., 64: 1331-1334.

On ifade A.A., Obiyan R.I., Onipede E., Adejumo O.A., Abu O.A., B abatune G.M. (1999 a). Assessment of the effects of supplementing rabbit diets with a culture of Saccharomyces cerevisiae using growth performance, blood composition and clinical enzyme activities. Anim. Feed. Sci. Technol., 77: 25-32.

On if a de A.A., O dunsi A.A., B ab a t und e G.M., Olored e B.R., Mu ma E. (1999 b). Comparison of the supplemental effects of Saccharomyces cerevisiae and antibiotics in low-protein and high-fiber diets to broiler chicken. Arch. Anim. Nutr., 52: 29-39.

O t s I., Hõ r a k P. (1996). Great tits Parus major trade health for reproduction. Proc. R. Soc. Lond. B 263: 1443-1447.

Öz s y B., Yalç in S. (2011). The effects of dietary supplementation of yeast culture on performance, blood parameters and immune system in broiler turkeys. Ankara Üniv. Vet. Fak. Derg., 58: $117-122$. 
P a n d a A.K., R e d d y M.R., P a r a h a j N.K. (2001). Dietary supplementation of probiotic on growth, serum cholesterol and gut microflora of broilers. Indian J. Anim. Sci., 71: 488-490.

P a r k B.H., F i krig S.M., S m i th w i c k E.M. (1968). Infection and nitroblue tetrazolium reduction by neutrophils. Lancet., pp. 532-534.

P a ry a d A., M a h m o u d i M. (2008). Effect of different levels of supplemental yeast (Saccharomyces cerevisiae) on performance, blood constituents and carcass characteristics of broiler chicks. Afr. J. Agr. Res., 12: 835-842.

R a a J. (1996). The use of immunostimulatory substances in fish and shellfish farming. Reviews in Fisheries Sci., 4: 229-288.

Regulation of the Minister of Agriculture and Rural Development dated 15 February 2010 on the requirements and handling procedures in keeping livestock species for which protection standards are specified in the provisions of the European Union (in Polish). Dz.U. nr 56, poz. 344.

Re is inger N., Ganner A., Masching S., Schatzmayr G., A p plegate T.J. (2012). Efficacy of a yeast derivative on broiler performance, intestinal morphology and blood profile. Livest. Sci., 143: 195-200.

S a i e d J.M., A l- J a b a ry Q.H., Tha lij K.M. (2011). Effect of dietary supplement yeast culture on production performance and hematological parameters in broiler chicks. Int. J. Poultry Sci., 10: 376-380.

S h a s h i d h a r a R.G., D e v e g o w d a G. (2003). Effect of dietary mannan oligosaccharide on broiler breeder production traits and immunity. Poultry Sci., 82: 1319-1325.

S i w i c ki A.K., D un i e r M. (1993). Quantification of antibody secreting cells to Yersinia ruckeri by ELISPOT assay after in vitro and in vivo immunization of rainbow trout (Oncorhynchus mykiss). Vet. Immunol. Immunopathol., 37: 73-80.

Soltanian S., Stuyven E., Cox E., Sorgeloos P., B o s s o e r P. (2009). $\beta$-glucan as immunostimulant in vertebrates and invertebrates. Crit. Rev. Microbiol., 35:109-138.

S o n g M., D i L u zi o N.R. (1979). Yeast glucan and immunotherapy of infectious diseases. In: Lysosomes in Applied Biology and Therapeutics, Dingle J.T., Jacques P.J., Shaw I.H. (eds). North Holland Press, Amsterdam, pp. 533-547.

S t a n l e y V.G., C r a y G., D a ly M., Kru e ga r W.F., S e t fo n A.E. (2004) An alternative to antibiotic based drugs in feed for enhancing performance of broilers grown on Eimeria Spp. Infected litter. Poultry Sci., 83: 39-44.

Ta bi d i M.H., M u kht a r A.M., E 1 - R a s h i ed E.L. (2013). Response of chicks for diet containing live Yeast as probiotic natural feed additive. J. Curr. Res. Sci., 1: 316-319.

Workman M., Holt P., Thy ka er J. (2013). Comparing cellular performance of Yarrowia lipolytica during growth on glucose and glycerol in submerged cultivations. AMB Express 3: 58 doi:10.1186/2191-0855-3-58.

Woźn i c a A., C z e c h A. (2010 a). Utilization of glycerol and yeast biomass produced from glycerol in the animal nutrition. Post. Nauk. Rol., 3: 133-141.

Woźn i c a A., C z e c h A. (2010 b). Utilization of glycerol and yeast biomass produced from glycerol in the animal nutrition. Monographic study "Agriculture of the 21 st century - new aspects of farming", Kraków, pp. 331-334.

Yalç in S., O z s o y B., E r o l H., YalÇ in S. (2008). Yeast culture supplementation to laying hen diets containing soybean meal or sunflower seed meal and its effects on performance, egg quality traits and blood chemistry. J. Appl. Poultry Res., 17: 229-236.

Received: 11 II 2014

Accepted: 13 VI 2014 